\title{
Lipoma de cono medular
}

\section{Conus Medullaris Lipoma}

\section{Pablo Cesar Guardado Ortiz, * Napoleón Urcuyo.**}

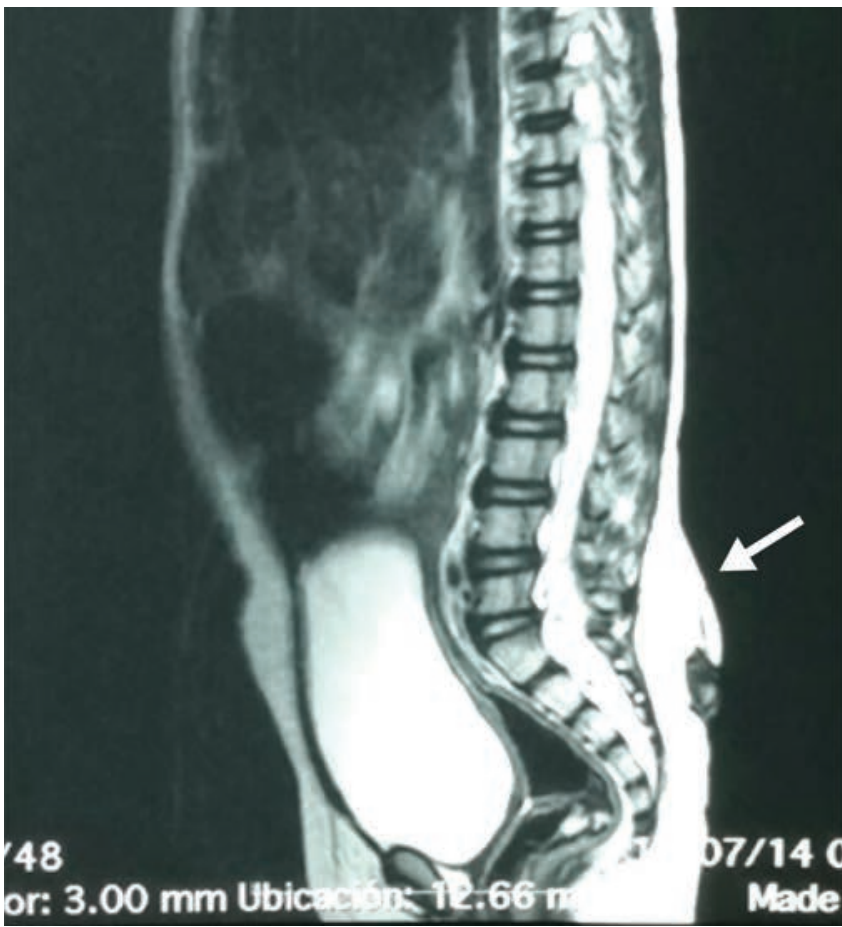

Preescolar femenina de 4 años de edad que desde su nacimiento presenta lesión dermoide en region lumbar el cual ha aumentado de tamaño, se realiza IRM de columna lumbar encontrando un lipoma del cono medular.

Los lipomas de cono medular son lesiones congénitas relativamente infrecuentes que se estima que afectan entre 1-5\% de la población. Su prevalencia estimada es de 1 caso por 1, 000,000 nacimientos. La forma de presentación clínica varía con la edad, en los niños más pequeños suele detectarse un estigma cutá-

\footnotetext{
* Médico Residente de 3er año del Postgrado Pediatría UNAH-VS.

* Neurocirujano en el Instituto Hondureño de Seguridad Social Región del Norte.

Dirigir correspondencia a: pabloguardado60@hotmail.com Recibido: 06 de junio 2015, Aprobado: 12 de junio 2015
}

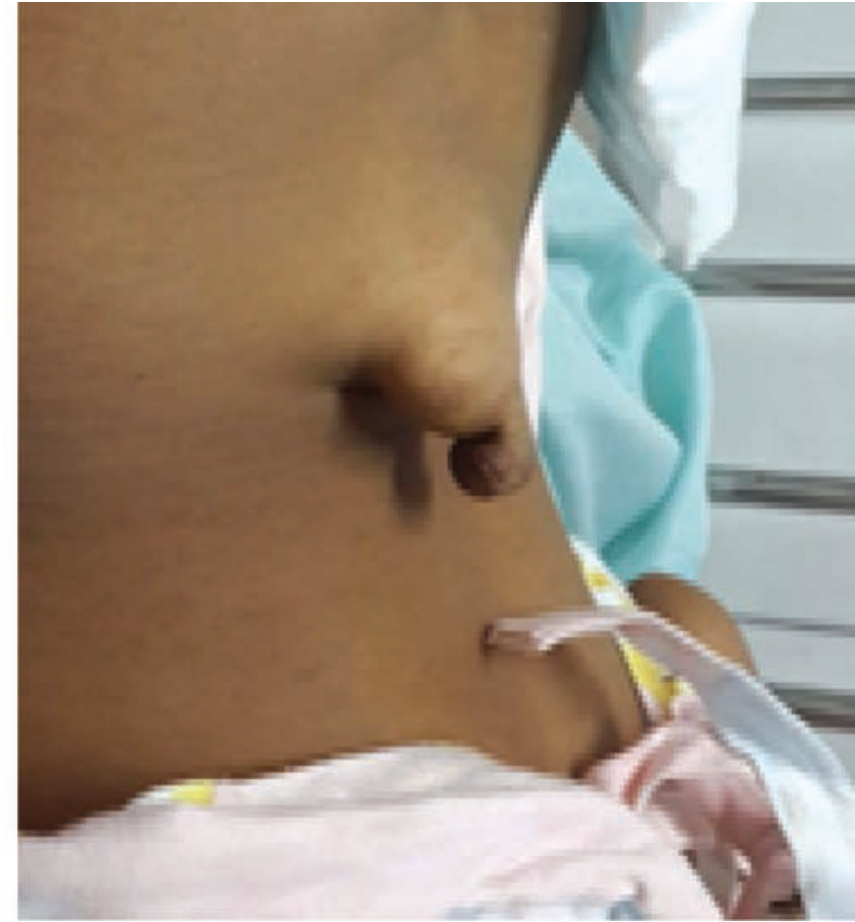

neo (seno dérmico, masa para-espinal, hemangioma capilar, meningocele atrésico, hirsutismo local, etc.). Hasta la mitad de los casos pueden presentar problemas urológicos como infecciones de repetición, incontinencia, retención, etc. La prueba diagnóstica de elección es la resonancia magnética, con alta sensibilidad y especificidad.

El tratamiento de estas lesiones es exclusivamente quirúrgico. En los pacientes con sintomatología y/o déficit neurológico no existen dudas sobre la indicación terapéutica, sin embargo en los pacientes con escasa sintomatología o sin ella, la decisión de la intervención quirúrgica es más comprometida ya que existe el riesgo de provocar lesión neurológica. 